\title{
Kişilerde Tükenmişlik ile Kişilik Özellikleri Arasında Yoga'nın Aracılık Etkisi
}

\author{
DOI: $10.26466 /$ opus.877462
}

\author{
Didem Tetik Küçükelçi \\ * Dr. Öğr. Üyesi, Gelişim Üniversitesi, İISF, İstanbul/Türkiye \\ E-Posta: didemkucukelci@yahoo.com.tr ORCID: 0000-0001-8911-4554
}

Öz

Bu çalışmadaki amaç, kişilik tiplerine göre bireylerin tükenmişlik durumlarında yoganın aracılık etkisinin sonuçların ortaya koymaktır. Çalışmada Burnout Tükenmişlik Ölçeği, Kişilik Özellikleri için Big Five Ölçeği ve Yoga Self-Efficacy (YSE) ölçeği kullanılmıştır. Çalışma için Ağustos 2019Eylül 2019 tarihleri arasında 165 kişi ile anket çalışması yapılmıştır. Anket çalışmaları internet üzerinden gerçekleştirilmiştir. Katıllımcılardan toplanan anket yanıtları SPSS 22.00 ile AMOS 22.00 paket programları ile analiz edilmiş ve sonuçlar değerlendirilmiştir. Ölçeklerin yapı geçerliliğinin sinanması için her bir ölçeğe doğrulayıc faktör analizi uygulanmıştır. Bu analiz sonucunda ölçeklerin uyum indeks değerleri kabul edilebilir sınırlar dahilinde bulunmuş ve doğrulayıcı faktör analizlerinin geçerli olduğu sonucu elde edilmiştir. Sonrasında ölçeklerin güvenilirliklerinin değerlendirilebilmesi için her bir ölçeğe ait Cronbach Alpha (Alfa) katsayıları hesaplanmıştır. Buna göre; Burnout Ölçeği, Kişilik özellikleri Ölçeği ve Yoga Self-Efficacy Ölçeklerinin Cronbach Alfaa değerleri sirasılyla (0,809), (0.786) ve $(0,875)$ şeklinde hesaplanmıştır. Ölçeklerin güvenilirlik değerleri yüksek güvenilir ve oldukça güvenilir seviyelerinde yer almıştır. Daha sonra YSE Ölçeğinin aracılık etkisinin araştırılması için AMOS programı kullanılmış ve elde edilen sonuçlar Sobel Testi ile tekrar değerlendirilmiştir. Yoganın tükenmişlik ölçeği olan Burnout ile kişilik tipleri arasında tam aracılık etkilerine sahip olduğu görülmektedir. Bu çalışma sonucunda yoganın kişiler üzerinde olumlu etkilerinin olduğu ve düzenli yoga egzersizlerinin kişilerde hem fiziksel hem de ruhsal olumlu katkıları olduğu sonucu çıkarilabilmektedir.

Anahtar Kelimeler: Burnout Tükenmişlik Ölçeği, YSE Ölçeği, Kişilik Tipleri, Bigfive, Yoga, Aracilik. 


\title{
Yoga's Mediation Role in Relation between Personality Types and Burnout Scale
}

\begin{abstract}
This work's purpose is demonstrade the consequenses of yoga's mediation effects on individual burnout situation according personal types. On this work burnout scale, for personal types Big Five Scale and Yoga Self-Efficacy (YSE) scale have been used. For this work, survey study has been done on 165 person between August 2019- September 2019. Survey work done through internet. All the collected survey answers analized by SPSS 22.00 and AMOS 22.00 programmes and evaluted the results. To examinate the validity of scales structures, factor analyse has been applied to each scale. As the result of this analyse, scales fitting indeks values have been found in acceptable limits and confirmed the factor analizes are valid. After all, Cronbach Alpha coefficient is calculated for each scale to evaluate the reliability of scales. According this: Burnout Scale, Personal Specialties Scale and Yoga Self-Efficacy Scales Cronbach Alpha Values are calculated in order of $(0,809),(0,786)$ and $(0,875)$.Scales reliability values are high and they are at the level of quite reliable. Than to search the effect of YSE scale mediation Amos programme has been used and the results evaluated again by Sobel test. It is clear that Burnout has full mediation effects with personal types. As a result of this work, yoga has positive effects on people and regular yoga egzersizes have positive contributions; menthal (spirituel) and phisical.
\end{abstract}

Keywords: Burnout Scale, Yoga, Bigfive Scale, YSES, Mediating Effect. 


\section{Giriş}

Yaşam koşullarının zorlaşması ve yaşamın hızlı akışı tükenmişlik kavramının kullanılmasını da yaygınlaştırmıştır. Bu nedenle son dönemlerde bu kavram ile ilgili çalışmalarda da artış görülmektedir.

Tükenmişlik kavramı, 1974 yıllında ilk defa Freudenberger tarafından ortaya atılmıştır. Freudenberger yoğun çalışma temposunun çalışanlar üzerindeki etkilerini fark ederek, bu etkinin oluşturduğu değişiklikleri, verimliliğe olan olumsuz yansımalarını araştırmaya başlamıştır ve tükenmişliği; başarısız olma, isteksizlik, yıpranma, hayata karşı olan enerjinin ve gücün azalması veya yerine getirilemeyen istekler ve hayal kırıklıkları sonucunda kişinin iç kaynaklarında oluşan tükenme hissiyatı, bitkinlik veya bıkkınlık olarak tanımlamıştır (Freudenberger, 1974). Tükenmişlik iş ortamındaki strese verilen bir tepkidir (Lee ve ark.,2013). Algül ise tükenmişliği, iş veya yaşam stresinin kişide fiziksel, ruhsal ve duygusal olarak yorgunluk ve bıkkınlık oluşturması, bireyin iş yaşantısından ve mesleğinden soğuması, kişinin işine, çalışma arkadaşlarına ve kendisine negatif duygular beslemesidir, şeklinde tanımlar (Algül,2014). Tükenmişliği bir durum olarak ele alan Maslach ve Jackson literatürde sık sık kullanılan Maslach Tükenmişlik Ölçeğini geliştirmişlerdir. Maslach'a göre tükenmişlik “işi gereği yoğun duygusal taleplere maruz kalan ve sürekli diğer insanlarla yüz yüze çalışmak durumunda olan kişilerde görülen fiziksel bitkinlik, uzun süreli yorgunluk, çaresizlik ve umutsuzluk duygularının, yapılan işe, hayata ve diğer insanlara karşı olumsuz tutumlarla yansıması ile oluşan bir sendrom"dur. Tükenmişlik; "işi gereği insanlarla yoğun bir ilişki içerisinde olan bireylerde görülen duygusal tükenme, duyarsızlaşma ve düşük kişisel başarı hissi" şeklinde boyutlandırılmıştır (Maslach ve Jackson, 1981).

Tükenmişlik sendromunda öncelikle birey, kendini duygusal anlamda yetersiz hissetmeye başlamakta ve bu yetersizlik hissi sonucunda duygusal olarak tükenme şeklinde sonuçlanmaktadır. Sonrasında kişi, başka insanlardan soyutlanmaya, uzak kalmaya ve sosyal ortamlardan uzaklaşmaya başlayarak duyarsızlaşma aşamasına geçmektedir. Duyarsızlaşma aşamasındaki kişi, sosyal ve iş ortamlarında kendini yetersiz görmeye başlamaktadır. Bununla birlikte birey; kendini 
başarısız, sınırlandırılmış, dışlanmış gibi olumsuz değerlendirmelere maruz bırakmakta ve zamanla kişisel başarıda düşüşü yaşamaya başlamaktadır (Cordes ve Dougherty, 1993; Maslach, Schaufeli ve Leiter, 2001; Maslach ve Zimbardo, 1982).

Tükenmişlik sendromunda olan kişilerde genellikle zayıf veya kötüye giden iş performansı, işe gitmek istememe, hiçbir şey yapmak istememe, herşeye karşı bıkkınlık hisleri gibi olumsuz durumlar ortaya çıkabilmektedir (Kahill, 1988; Lee, Lim, Yang, Lee, 2011). Tükenmişlik sendromunda olan kişilerde yaratıcılık yok olur ve kişiler herhangi bir durum için çaba göstermezler (Aslan, 1997). Anksiyete düzeyleri yükselir, bu durumlarında sempatik sistem etkinliğini sürdürür savaş ve kaç tepkisi ile birlikte fizyolojik semptomlar ortaya çıkar, iç salgı bezleri olağan dışı çalışır bedende gerginlikler artar. Ancak, parasempatik sistem devreye girmez. Olağan parasempatik sistemin devreye giremediği kişiler rahatlayamazlar, dinlenemezler öyle ki uyumak bile dinlendirici etkiye sahip olmaz. Kişilerin bedenlerinde oluşan ve sürekli hale gelen gerginlikler ağrılara sebep olur. Mevcut fizyolojik sorunlar kaygının etkisi ile daha da artar hale gelir (Şahin, 2019a). Vücudumuzdaki duyumlar, kaygı etkisi ile daha da yoğunlaşan gerginlikler hatırlamak istemediğimiz bazı anıları, olayları, ihtiyaçları ya da korkuları hatırlatıyorsa, o zaman kendimizi bu duyumlara kapatır, onları görmezden gelir veya onları inkâr ederiz (Şahin, 2019b). Bunların sonucunda da çalışanların çalışma kalitesi olumsuz etkilenir (Kaçmaz, 2005).

Daha ileriki aşamalarda kişilerde tükenmişlik durumunun etkilerine bağlı olarak anksiyete, depresyon, mide ile ilgili hastalıklar, uykusuzluk, huzursuzluk, kalp ve damar hastalıkları gibi sağlık problemleri de görülebilmektedir (Carrola, Yu, Sass, Lee, 2012 ; Lee ve ark., 2011).

Yoga, Sanskrit dilinde bir olmak, birleşmek, bütün olmak anlamlarına gelen bir sözcüktür ve "yuj" kökünden türetilmiştir (Patanjali, 2011). Yoga, kişinin kendi iç veya öz kişiliğini keşfedebilmesi, kendini zihinsel olarak da bilebilmesi, yüksek bilinç denen hedefe erebilmesi ve farkındalıkla yaşayabilmesi için kullanabileceği bir yoldur. Yoga bir düşünce şeklidir, bir felsefedir ve aynı zamanda bir yaşam disiplinidir (Rathfisch G., 2015). Yogada temel anlayış; nefes, zihin ile bedenin uyumudur. Bundan dolayı yoga pratikleri; nefes teknikleri olarak 
tanımlanan pranayama, zihin çalışmaları ve asana denen beden duruşlarını temel almaktadır.

Yoga, yoganın özdeyişleri olarak da tanımlanan "Yoga Sutralar"da ayrıntılı olarak anlatılmaktadır. Yoga sutraların, Patanjali tarafından M.Ö.4 - M.S.4. yüzyılları arasında oluşturulduğu tahmin edilmektedir. Sutralar, yoga uygulayanlar ve yogayı öğrenmek isteyenler için bir rehber niteliğindedir. Yoganın ne olduğu, nasıl uygulanabileceği, aşamaları konularında aydınlatıcı niteliktedir.

Yoga bedensel, ruhsal, zihinsel ve etik öğretilerle harmanlanmış sekiz aşamalı bir sistemdir. Bu sekiz aşama, kişinin özüne dönüş yolculuğunda ilerleyebilmesi için üzerinde düşünmesi, anlaması ve uygulayabilmesi gereken basamaklardır. Bunlar; yamalar, niyamalar, duruş olan asanalar, nefes olan pranayama, prathayara, dhrana, dhyana, samadhidir (Patanjali, 2011). Yamalar; yalan, her türlü hırsızlık, şiddet, doyumsuzluk, şehvet, saplantı gibi uzak durulması gereken olumsuz davranışları, ahlak ile ilgili kurallara bağlı kalmak ve başkalarına zarar vermemek gibi maddeler içermektedir ve beş başlık halinde incelenmektedir:

1. Ahimsa: Her türlü şiddetten uzak olmaktır. Buna kişinin kendisine uyguladığ

2. Satya: Bireyin kendisine ve çevresindekilere dürüst olmasıdır.

3. Asteya: Hırsızlıktan sakınma ve çalmamaktır. Fikir hırsızlığı, haksız kazanç, ödünç alınan bir nesnenin teslim edilmemesi, söz verilen saatte olunması gereken yerde olunmaması yani zaman hırsızlığı Asteya' ya örnektir.

4. Brahmaçarya: Arzu ve haz duygularının denetimini içermektedir. Aparigraha: Biriktirmemek, ihtiyaç dışındakileri istiflememek durumudur.

$\mathrm{Bu}$ kullanılmayan giysiler, eşyalar olabilir veya zihinde dönüp dolaşan her türlü duygu olabilir.

Niyama, kişinin öz disiplinine yönelik uyması gereken kurallardan oluşmaktadır. Saflık, sadelik, beden-ruh-zihin temizliği, nefse hakim olma, hoşnutluk, eğitim gibi belli başlı uyulması gereken disiplinlerden oluşmaktadır ve beş bölümde anlatılır:

1. Sauça, saflık ve temizlik ile ilgili kurallardır. Hem zihinsel hem de bedensel bir temizlik sözkonusudur. Zihni gereksiz ve 
faydasız her türlü düşünceden arındırmak, bedene alınan gıdaların faydalı ve saf olanını seçmek de Sauça için örneklerdir.

2. Santoşa; yetinme, şükretmek, halinden memnun olmak ve kabullenmek durumudur.

3. Tapas çabalama durumudur. Tapas ile beden, zihin saflaşır ve anda kalabilmek söz konusu olabilir.

4. Svadhyaya kişinin kendini eğitmesi ve gereken bilgilere ulaşması durumudur.

5. İshvara Pranidhana mutlak varlığı algılama durumuna verilen addir.

Asana duruş demektir. Bedenin belli duruşlarda tutularak fiziksel, enerjetik ve zihinsel fayda sağlamasına yönelik eğitilmesidir (Patanjali, 2011).

Pranayama, kadim nefes teknikleri olarak da adlandırılabilen beden ve zihni iyileştirmeye, sağlıklı olmaya yönlendiren nefes çalışmalarını kapsamaktadır. Pranayama, anlamı yaşam enerjisi olan prana ile anlamı ustalaşmak olan yama seslerinden türemiştir. Kadim bilgelikte yaşam gücünü anlatan enerjide ustalaşmak anlamına gelmektedir (Şinik E.,2016). Yaşam enerjisi için doğru ve bilinçli nefes alıp vermek çok önemlidir. Son yıllarda nefes üzerine yapılan araştırmalara göre; düzenli uygulanan nefes egzersizleri huzursuzluk, öksürük şikayetleri, stres, dikkat eksikliği, depresyon, anksiyete, mutsuzluk, uykusuzluk, astım, kabızlık gibi sindirim sistemi hastalıklarına, boyunda, omurgada veya sırtta oluşan ağrılara, solunum sistemi hastalıkları gibi birçok bedensel, ruhsal, duygusal ve zihinsel rahatsızlıklara iyi gelmektedir (Joshi, 1983).

Yoga düzenli hayata entegre edildiğinde ruhsal, bedensel, zihinsel birçok yararları bulunmaktadır. Strese dair de olumlu etkileri olduğu bilinmektedir (Atılgan, Tarakci, Polat, Algun, 2015; Salmon, Lush, Jablonski, Sephton, 2009). Yoganın kronikleşen kalp, akciğer veya solunum hastalıkları, yüksek veya düzensiz tansiyon, şeker hastalıkları, diyabet, astım, alerjik astım, omurga rahatsızlıkları, kronik hale gelmiş yorgunluk, ağrı, dikkat dağınıklığı, kramplar, uykusuzluk veya uyku ile ilgili sıkıntılar, depresyon, huzursuzluk, anksiyete gibi bedensel, zihinsel ve ruhsal birçok rahatsızlığa iyi geldiği çalışmalarla desteklenmekte ve bu çalışmalar her gün daha da artmaktadır (Baş , 1998; Coote, Garrett, Hogan , Larkin, Saunders , 2009 ; Evans , Carter , 
Panico , Kimble , Morlock, Spears , 2010; Field , 2011; Pal, Srivastava , Tiwari et al., 2011; Hall , Verheyden , Ashburn , 2011; Güler , 2010; Newham , Wittkowski , Hurley, Aplin , Westwood , 2014). Son dönemde hamilelik döneminde ve sonrası için de yoga tavsiye edilmektedir (Alkan E, Özçoban, 2017).

Pratyahara, duyu organlarının kontrolünün sağlanması sonucunda iç dünyaya odaklanmak demektir. Zihin, diş etkenlerden arındırılarak sakinleştirilir. Dharana, zihni bedende seçilebilecek bir bilinçte tutmak, konsantrasyonu güçlendirmek, dikkati tek bir objede odaklayabilmektir.

Dikkat, bir noktaya yoğunlaştırdığında Dhyana'ya geçilir. Konsantrasyon sirasında zihin tek bir noktaya yönlendirilir. Dhyana, meditasyon demektir. Meditasyon uygulamasını düzenli uygulayan kişilerde, strese bağlı gerginlik durumlarında azalma; buna karşılık, farkındalıklarında, sevgi, sakinlik ve şefkat durumlarında artma olduğu görülmüştür. Ayrıca düzenli meditasyon uygulamalarını hayatlarına dahil eden bireylerin öncesine kıyasla daha huzurlu ve daha mutlu oldukları söylenmektedir (Hewitt, 1994) En son basamak olarak ise Samadhi'den söz edilmektedir. Derin dalış şeklinde de adlandırılabilmektedir. Bedensel duyular aracilığı ile beden gözlemlenirken, akıl ile ruh uyanık kalır (Atılgan, Tarakçı, Algun, Polat, 2015; Isherwood ,2006; Nagarathna, Nagendra, Gürelman , 2014).

Yoga felsefesi asana, pranayama ve meditasyon olmak üzere üç ana temelden oluşmaktadır (Sorosky, Stilp, Akuthota ,2008).

Yukarıda belirtilen 8 basamak yogadaki 3 temel esas olan beden, nefes ve zihni işaret eder. Yogada, yoganın babası olarak bilinen Krishnamacharya'ya göre üç temel esas aşağıdaki gibi özetlenebilmektedir:

1. Beden: Yogada bedene yönelik duruşlara asana adı verilmektedir. Düzenli bedensel aktivite veya pratik yapanlar, zihinsel dikkati de yükseltmek için asanaları nefes ile uyumlandırırlar.

2. Nefes: Nefes ile ilgili çalışmalardır. Buna kadim geleneklerde pranayama denmektedir.

3. Zihin: Meditasyondaki haldir. Meditasyon en genel tanımı ise zihinsel sessizlik halidir (Desikachar, 1999).

Bu çalışmadaki yoga self-efficacy ölçeği, Birdee, Sohl ile Wallston tarafından 2016 senesinde geliştirilmiştir. Ölçek yoganın üç temel esası 
olarak belirlenen beden, zihin ve nefes ile ilgili maddeler içermektedir. Birdee ve arkadaşları ölçeğin geliştirilmesi aşamasında Desikachar'ın oluşturduğu 21 maddeli self-efficacy maddeleri ile buna dair teorisini kullanmışlardır (Bandura, 1997; Schwarzer, 2001). Ölçekte bulunan maddelerle ilgili çalışmalar sonucunda, maddeler yogayı yansıtacak şekilde beden, nefes ve zihin şeklinde üç ana başlık altında toplamış ve oluşturulan bu 32 maddeli ölçek birçok uzman ve Krishnamacharya'nın öğrencilerinden seçilmiş yoga eğitmenleri tarafından değerlendirilmiştir. Bunun neticesinde de ölçek 14 madde şeklinde ele alınmıştır (Birdee, Sohl ve Wallston, 2016).

Yoga ölçeğinin geliştirilebilmesi, oluşturulan maddelerin uygunluğunun saptanması için Krishnamacharya ekolünden gelen 3 yoga eğitmeninden destek alınmıştır. Yoga eğitmenleri ile yapılan çalışmalar sonucunda ölçek tekrar düzenlenmiştir. Ölçek, gönüllü kişilere dokuzlu likert tipli olarak sunulmuştur. Ölçek yanıtları 'kesinlikle katılmıyorum'dan 'tamamen katılıyorum'a doğru ağırlıklandırılmıştır. Karşılıklı sözlü olarak yapılan uygulama esnasında katılımcıların bilişsel özellikleri de dikkate alınmış ve ölçek maddelerinin anlaşılıp anlaşılama durumlarına göre düzenleme yapılmış ve sonunda 13 maddelik Yoga self-efficacy ölçeği elde edilmiştir (Birdee, Sohl, Wallston, 2016).

Kişilik; genetik faktörler, aile, sosyal çevre, değişen yaşam koşulları gibi birçok etkeni aynı anda içinde barındırabilen ve hayat boyu devam edebilen bir süreçtir. Bu geniş tanımdan dolayı da kişiliği tanımlamaya, açıklamaya çalışan birçok yaklaşım bulunmaktadır.

Kişilik birçok faktörü eşzamanlı olarak içinde bulunduran bir evrimsel süreçtir. Genetik, biyolojik, çevresel koşullar, sosyal çevre, değişen yaşam koşulları gibi birçok kavramı içine almaktadır. $\mathrm{Bu}$ nedenlerle kişiliği açıklamaya çalışan çok sayıda yaklaşım bulunmaktadır ve hala araştırılmaya devam edilmektedir. Burger'a göre kişilik; kişilik içindeki süreçler ve kişiye özgü tutarlı davranışlar bütünüdür (2006). Burger bu tanımla, insanlarla ortak olabilecek yönlerimize değil, bizi diğerlerinden ayıran belirleyici özelliklere vurgu yapmaktadir.

$\mathrm{Bu}$ düşünce sistemine göre; kişiliği belli başlıklar altında tanımlayabilmek için çeşitli kuramlar oluşturulmuştur. Bu yaklaşımlar 
çerçevesinde, beş faktör kuramı daha çok kabul görmektedir (Goldberg, 1990; McCrae, Costa, 2003). Bu kuramcılar diğer kişilik kuramcılarından bazı farklı özellikler göstermektedirler. Ayırıcı özellik kuramcıları olarak nitelendirilen bu kuramcıların amaçları, davranışa yönelik değişim veya gelişimi kestirmek değildir, davranışı tanımlamaya çalışmaktır. Terapistten çok akademik araştırmacı olarak çalışmaktadırlar. Ayırıcı özellik kuramcıları, çalışmalarında elde ettikleri faktör analizi sonuçları ile çeşitli kişilik verilerini beş boyut altında toplamışlardır (Costa ve McCrea,1988; Goldberg,1990; Noller, Law ve Comrey, 1987; Peabody ve Goldberg, 1989). Boyutlar için farklı görüşler olsa da McCrea ve Costa, 2003 yılında uyumluluk, dişadönüklük, öz-disiplin, deneyime açıklık ve nevrotik şeklinde beş temel kişilik özelliğini bulmuşlardır.

Uyumluluk (Agreeableness) boyutundaki kişiler; iyi huylu, eli açık, uysal, güvenilir, yardımsever, cömert ve sakin olarak tanımlanmıştır. Uyumluluk boyutunda skoru yüksek olan bireylerin işbirliğine, skoru düşük olanların ise rekabete yatkın oldukları söylenmektedir (McCrea ve Costa, 2003).

Dışadönüklük (Extraversion) skorları yüksek olan bireyler; konuşkan, eğlenceli, şakacı, sevecen, girişken ve sosyaldir. Düşük olanlar ise içedönük, pasif, çekingen, sessiz, edilgen ve yalnızlığı seven bireylerdir (McCrea ve Costa, 2003).

Özdisiplin (Conscientiousness) boyutunda skoru yüksek olan bireylerin çalışkan, düzenli, planlamaya yatkın, ihtiraslı oldukları; buna karşılık düşük skorlu bireylerin işi ciddiye almayan, amaçsız, dikkatsiz, dağınık, oldukları gözlemlenmiştir (McCrea ve Costa, 2003).

Duygusal İstikrar (Emotional Stability) boyutunda, yüksek skorlu bireylerin bağımsız düşüncelere sahip ve geleneksel değerleri sorgulama eğiliminde oldukları görülmüştür (McCrea ve Costa, 2003).

Nevrotik(Neoroticism) boyutunda skoru yüksek olanlar kaygıll, güvensiz, kendine aciyan, duygusal ve stresle ilgili psikolojik hastalıklara yatkındırlar (McCrea ve Costa, 2003). 


\section{Yöntem}

\section{Örneklem}

Ağustos 2019-Eylül 2019 ayları arasında kolayda örneklem metodu kullanılarak, yüzyüze 170 kişi ile anket yapılmıştır. Ancak inceleme yapıldıktan sonra 5 anketin doldurma oranları çok düşük bulunmuştur ve bu anketler analiz dışı tutulmuştur. Bunun sonucunda anket sayısı 165 olarak kabul edilmiştir. Ayrıntılar Tablo 1'de tablolanmıştır.

Tablo 1. Katılımcılara Ait Demografik Özellikler

\begin{tabular}{llll}
\hline & & $\mathbf{N} \mathbf{( 1 6 5 )}$ & $\mathbf{\%} \mathbf{N}$ \\
\hline GND & Erkk & 23 & $13,9 \%$ \\
& Kadın & 142 & $86,1 \%$ \\
\hline AGE & 25 'ten az & 1 & $0,6 \%$ \\
& $25-29$ arası & 12 & $7,3 \%$ \\
& $30-34$ arası & 45 & $27,3 \%$ \\
& 35 ve üzeri & 107 & $64,8 \%$ \\
\hline EDC & Ilk/ortaokul & 1 & $0,6 \%$ \\
& Lise & 7 & $4,2 \%$ \\
& Üniversite & 109 & $66,1 \%$ \\
& master/doktora & 48 & $29,1 \%$ \\
\hline \multirow{2}{*}{ York } & Yönetici & 91 & $55,2 \%$ \\
& Meslek elemanı & 25 & $15,2 \%$ \\
& Öğretmen-eğitmen & 30 & $18,2 \%$ \\
& Diğer & 19 & $11,5 \%$ \\
\hline EXP & 5 yıldan az & 18 & $10,9 \%$ \\
& $5-10$ yıl & 35 & $21,2 \%$ \\
& $11-16$ & 41 & $24,8 \%$ \\
& 16 yıl ve üzeri & 71 & $43,0 \%$ \\
\hline
\end{tabular}

Katılımcıların 142'si kadın, 23'ü erkektir. Yaşları 35 ve üzerinde olan 107 kişi, yaşları 30 ile 34 arasında olan 45 katılımcı bulunmaktadır. Eğitim düzeyi üniversite mezunu olan 109 kişi, iş tecrübesi 16 yıl ve üzerinde olan 71 katılımcı bulunmaktadır.

\section{Verilerin Analizi}

Araştırma kapsamında toplanan anket cevapları SPSS 24.00 ve AMOS 24.00 programları kullanılarak analize alınmış ve analizler ile elde edilen 
tablolar yorumlanmıştır. Araştırmanın ölçeklerine ait doğrulayıcı faktör analizleri AMOS 22.00 programında yapılmış ve her bir ölçeğe ait Cronbach's Alpha katsayıları hesaplanmıştır. Ayrıca, yapısal eşitlik modellemesi ile aracılık etkileri de AMOS programında uygulanan analizlerle araştırılmıştır.

\section{Ölçeklerin Güvenilirlik- İç Tutarlılık Değerleri}

Araştırmalarda kullanılan ölçeklerin geçerlik ve güvenilirlik analizlerinin sonuçları araştırma açısından çok önemli bir yere sahiptir. Araştırma kapsamındaki ölçekler kullanılmadan önce mutlaka güvenilirlik ve geçerlik bakımından kontrol edilmelidir. Bir ölçek için güvenilirlik, kullanılan ölçeğin aynı örnekleme farklı zaman dilimlerinde uygulandığı zamanlarda aynı sonuçları vermesidir. Aynı zamanda güvenilirlik, özellikleri veya bir değişkeni değerlendirmek için yöneltilen maddelerin bilinçli olarak cevaplanıp cevaplanmadığının bir göstergesi olarak da kabul edilmektedir (Özdoğan ve Tüzün, 2007). Bu araştırmada, güvenilirliğin analizi için Cronbach's Alfa katsayısı kullanılmıştır. Cronbach's Alpha katsayısı aynı zamanda sorular arasındaki ilişkinin düzeyini de belirtir. Cronbach's Alfa katsayısı $(0,70)$ ve daha yüksek ise ölçeğin güvenilir olduğu sonucuna ulaşılır.

Tablo 2. Cronbach's Alfa Katsayılarına İlişkin Sınıflama

\begin{tabular}{ll}
\hline Cronbach's Alpha Değeri & Yorumlaması \\
\hline 0,80 ile 1,00 arasında & Yüksek Güvenilirlik Seviyesi \\
0,60 ile 0,80 arasında & Oldukça güvenilir Seviyede \\
0,40 ile 0,60 arasinda & Güvenilirlik düşük Seviyede \\
0,40 ve daha düşük & Ölçek Güvenilir değil \\
\hline
\end{tabular}

Bir ölçekteki geçerlik ise, kullanılan ölçeğin ölçülmek istenen değişkeni ne kadar ölçtügüne ilişkin bir değerlendirmedir. Ancak güvenilirlik analizinde olduğu gibi geçerlilik analizinde kullanılan belli bir katsayı bulunmamaktadır. Bu nedenle geçerlilik analizi daha çok kuramsal olarak ele alınmaktadır (Kalaycı, 2006, s.405). 
Tablo 3. Kullanılan Ölçeklerin Cronbach's Alpha Katsayıları

\begin{tabular}{lll}
\hline Ölçek & Madde Sayıs & Cronbach's Alpha \\
\hline Big Five (BF) & 10 & .786 \\
Extraversion (EXT) & 2 & .771 \\
Agreeableness (AGR) & 3 & .765 \\
Conscientiousness (CON) & 3 & .745 \\
Emotional Stability (EM) & 2 & .712 \\
Burnout (BO) & 15 & .809 \\
Emotional Exhaustion (EE) & 8 & .804 \\
Depersonalization (DP) & 2 & .790 \\
Personal Accomplishment (PA) & 5 & .811 \\
Yoga Self-Efficacy Scale (YSE) & 12 & .875 \\
Body (BD) & 5 & .856 \\
Breath (BRT) & 4 & .823 \\
Mind (MND) & 3 & .812 \\
\hline
\end{tabular}

Araştırma için katılımcılara uygulanan ölçeklerden kişilik Big Five Ölçeği(.786) güvenilirlik katsayısı ile oldukça güvenilir seviyede yer almaktadır. Burnout ölçeği için güvenilirlik katsayısı (.809) ve Yoga SelfEfficacy Ölçeği için ise bu katsayı (.875) olarak hesaplanmıştır. Bu değerler, yüksek güvenilirlik düzeyinde yer almaktadır.

Big Five (BF) ölçeğinin alt boyutlarında ise Dışa Dönüklük(Extraversion) (.771), Uyumluluk(Agreeableness) (.765), Öz Disiplinli(Conscientiousness) (.745) ve Duygusal İstikrar(Emotional Stability) (.712) güvenilirlik katsayıları elde edildiğinden bu boyutların tamamı oldukça güvenilir seviyede yer almaktadır.

Burnout (BO) ölçeğinin alt boyutlarında ise Duygusal Tükenme(Emotional Exhaustion) (.804); Kişisel Başarı(Personal Accomplishment) (.811) boyutları bu katsayılarla yüksek güvenilirlik seviyesinde yer alırken, Duyarsızlaşma(Depersonalization) (.790) boyutu ise oldukça güvenilir seviyede yer almaktadır.

\section{Modelde Kullanılan Ölçeklere Ait Doğrulayıcı Faktör Analizleri}

Doğrulayıc1 Faktör Analizi ile her bir ölçek için kurulan modellerin anlamlı olup olmadığı araştırılmaktadır. Bunun için AMOS 22.00 paket programı kullanılmıştır. Sonuçlara bakıldığında, ölçüm modellerinin kabul edilebilir sınırlar içerisinde olduğu görülmüştür. Sonrasında, tam 
modelin uygunluğunun değerlendirilebilmesi adına iyi uyum kriterleri esas alınmıştır.

Örneklemin eleman sayısı arttıkça, Ki-Kare $\left(x^{2}\right)$ de artmakta ve KiKare $\left(x^{2}\right)$ testinin istatistiksel olarak anlamlılık de düzeyi düşük çıkmaktadır (Bagozzi, 1999; Bollen, 1989 ; Fornell ve Larcker, 1981). Araştırmada kullanılan ölçeklerin DF analizlerinin sonuçlarının araştırılmasında ve genel test edilen araştırma modellerinin uygunluklarına; serbestlik derecesi ile düzeltilmiş Ki- Kare Değeri (KiKare değeri/Serbestlik derecesi) ile diğer uyum iyiliği indeksleri, standartlaştırılmış artık (residual) kovaryans matrisinde bulunan değerlerin irdelenmesi sonucu ile karara ulaşılmıştır (Cem, Meydan,2011).

Tablo 4. Doğrulayıcı Faktör Analizindeki Uyum İyiliği İndeksleri ve Uyum Değerleri

\begin{tabular}{lll}
\hline İndeksler & İyi Uyum Değeri & Kabul Edilebilir Uyum Aralığ \\
\hline$\chi 2 / \mathrm{df}$ & $0 \leq \chi 2 / \mathrm{df} \leq 2$ & $2<\chi 2 / \mathrm{df} \leq 3$ \\
GFI & $\geq 0,900$ & $0,85-0,89$ \\
CFI & $\geq 0,970$ & $, \geq 0,95$ \\
SRMR & $\leq 0,050$ & $0,06 \leq$ SRMR $\leq 0,08$ \\
RMSEA & $\leq 0,050$ & $0,06 \leq$ RMSEA $\leq 0,08$ \\
\hline
\end{tabular}

Big five (BF) Ölçeği için Doğrulayıcı Faktör Analizi: 16 maddeli Big five ölçeğinden 1 madde madde faktör yüklerinin (0.50) değerinden düşük olması dolayısıyla analizden çıkarılmıştır. Kalan 10 maddenin kullanılmasıyla yapılan Doğrulayıcı Faktör Analizi DFA' da madde yükü (faktör) değerleri $(0.57 ; 0.80)$ arasındadır.

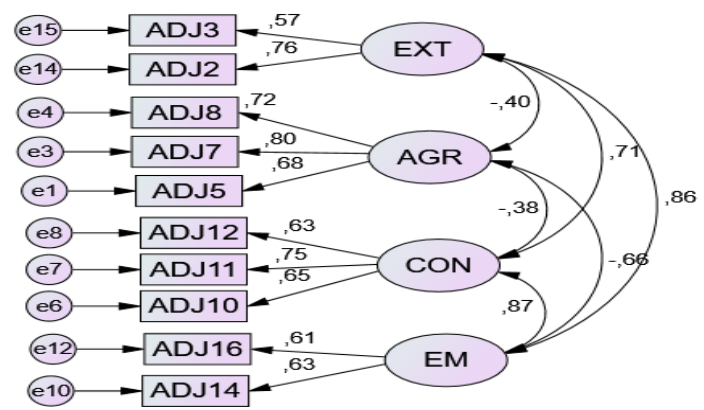

Şekil 1. Big Five (BF) Ölçeği için Doğrulayıcı Faktör Analizi 
Doğrulayıcı faktör analizinde model test değerleri ki-kare (45.51), $\mathrm{x}^{2} / \mathrm{df}(1,625)$ bulunduğundan DFA' nın anlamlı olduğu sonucu elde edilmektedir. Modele ait uyum indeks değerleri olan GFI (,949),CFI $(950)$, SRMR $(, 075)$, RMSEA (,062) kabul edilebilir değerler içerisinde olduğundan dolayı ölçeğin doğrulayıcı faktör analizinin geçerli olduğu söylenmektedir.

Burnout (BO) Ölçeğinin Doğrulayıcı Faktör Analizi: 22 maddeli Burnout (BO) ölçeğinden 7 madde, madde faktör yükleri çok düşük bulunduğundan analiz dişı tutulmuştur. Kalan 15 maddeyle gerçekleştirilen DFA'da madde faktörünün yük değerlerinin $(0,51 ; 0,66)$ sınırları içerisinde bulunmuştur.

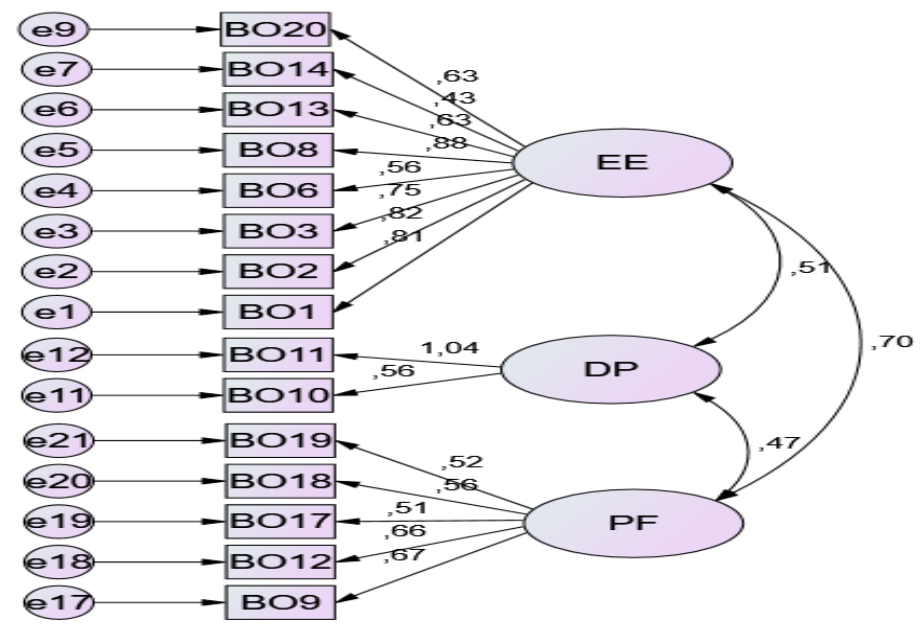

Şekil 2. Burnout (BO) Ölçeği için Doğrulayıcı Faktör Analizi

Doğrulayıcı faktör analizinde kullanılan model test değerleri ki-kare (208.21), x²/df (2.393) bulunduğundan $\mathrm{DFA}^{\prime}$ nın anlamlı olduğu sonucuna ulaşılmaktadır. Modelin uyum indeks değerleri olan GFI (,911), CFI (,954), SRMR (,069), RMSEA (,072) kabul edilebilir sinırlar içerisinde bulunduğundan dolayı Big Five ölçeğinin Doğrulayıcı Faktör analizi geçerlidir denebilir. 
Yoga Self-Efficacy Scale (YSE) için Doğrulayıcı Faktör Analizi: 13 maddeli Yoga Self-Efficacy ölçeğinden 1 maddenin madde faktör yükü istenen seviyenin altında bulunmuştur. Kalan 12 madde ile gerçekleştirilen DFA sonucunda, madde faktör yük sonuçları $(.53 ; .90)$ sinırlarında bulunmuştur.

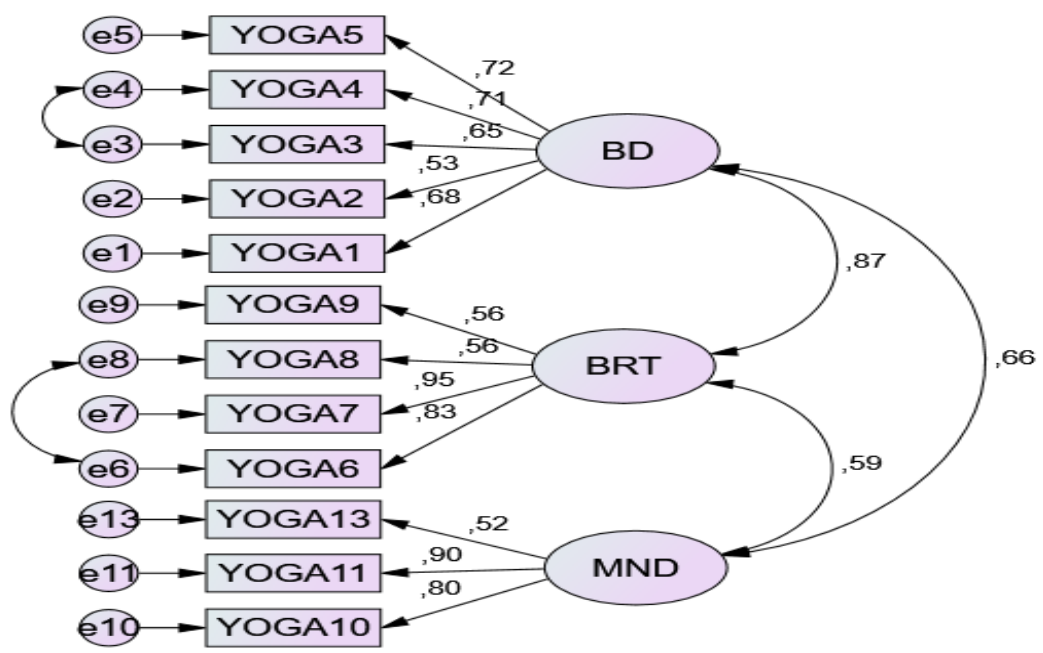

Şekil 3. Yoga Self-Efficacy Ölçeği için DFA

Doğrulayıcı faktör analizinde kullanılan model testlerinin kriterleri; Ki-Kare $x^{2}$ (87.70), $x^{2} / \mathrm{df}$ (1.993) olarak hesaplandığından dolayı yapılan DFA' nın anlamlı değerlerde olduğu söylenebilir. Modelin uyum indeks değerleri GFI $(0,923)$, CFI $(0,954)$, SRMR $(0,069)$, RMSEA $(0,078)$ kabul edilebilir sınırlar içinde bulunduğundan Yoga Self-Efficacy ölçeğinin Doğrulayıcı Faktör analizi geçerlidir denebilir.

\section{Amos programı ile Mediatör Değişken Etkisi Araştırması}

Craig, (2009)'e göre mediatör veya moderatör değişkenlerin olup olmadığını kontrol eden modeller yapısal eşitlik modellerinin temelini oluşturmaktadır. Gerçekte mediatör veya moderatör değişkenlerin varlığını kontrol eden modeller basit yapısal eşitlik modelleri olarak düşünülebilmektedir. $\mathrm{Bu}$ nedenle, gizil değişkenler bulunan daha 
karmaşık olarak nitelendirilebilen yapısal eşitlik modellerinin nasıl analiz edildiklerini anlamak önemli bulunmaktadır (Bayram, 2013).

Söz edilen değişkenler aşağıda sıralanmış koşulları yerine getirdiğinde mediatör (arabulucu, aracı, medyatör) değişken adını almaktadır (Baron ve Kenny,1986; MacKinnon, 2008).

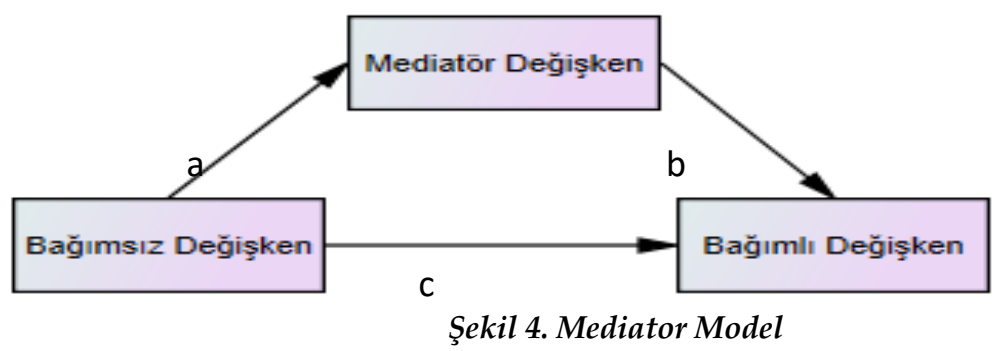

- Bağımsız değişkenin düzeyinde gerçekleşen değişimler ile mediatör değişken olduğu düşünülen değişkendeki değişimlerin nedenlerini anlamlı olacak şekilde açıkladığında (Şekil 4'de a yolu),

- Mediatör değişken oluşmuş olan değişimler, bağımlı değişkendeki değişimlerin sebeplerini anlamlı bir şekilde açıkladığında (Şekil 4'de b yolu),

- a ile b yolları kontrol değişkeni olarak ele alınıp, bağımlı bağımsız değişkenler arasında olan ve önceden anlamlı olan ilişki artık anlamlı çıkmıyor ise (Şekil 4'de c yolu), c yolu sıfıra yaklaştığı zaman tek ve baskın denebilecek bir mediatörün var olduğu, eğer c yolu sıfırdan farklı ise çoklu mediatör faktörlerin etkisinin varlığından söz edilebilmektedir.

Araştırma modelinde yukarıda anlatılan şartların oluşup oluşmadığını görebilmek için bağımsız değişkenlerle medyator değişken arasındaki ilişkiler, medyator değişkenle bağımlı değişken arasındaki ilişkiler ve bağımsız değişkenle bağımlı değişkenler arasındaki tekil ilişkilerin anlamlı olup olmadığı incelenmiştir. 
Tablo 5. Bă̆ımsız, Bă̆ımlı Ve Mediator Değişken Arasındaki Tekil Etki Değerleri

\begin{tabular}{llllllll}
\hline Etki & Eksojen & Etki & Endojen & $\beta$ & Std. $\beta$ & CR & p \\
\hline \multirow{3}{*}{ Bağımsız $\rightarrow$ Bağımlı } & EXT & $\rightarrow$ & BO &,- 885 &,- 387 & $-3,202$ &, $001^{* *}$ \\
& CON & $\rightarrow$ & BO &,- 350 &,- 340 & $-3,020$ &, $003^{* *}$ \\
& AGR & $\rightarrow$ & BO &, 280 &, 267 & 2,772 &, $006^{* *}$ \\
& EM & $\rightarrow$ & BO &, 056 &, 083 &, 202 &, 840 \\
& EM & $\rightarrow$ & YSE &, 599 &, 471 & 3,169 &, $002^{* *}$ \\
& CON & $\rightarrow$ & YSE &,- 288 &,- 42 & $-3,970$ &, $000^{* * *}$ \\
Bağımsız $\rightarrow$ Mediator & AGR & $\rightarrow$ & YSE &, 303 &, 45 & 4,151 &, $000^{* * *}$ \\
& EXT & $\rightarrow$ & YSE &, 425 &, 119 & 3,588 &, $000^{* * *}$ \\
Mediator $\rightarrow$ Bağımlı & YSE & $\rightarrow$ & BO & $-1,099$ &,- 583 & $-5,265$ &, $000^{* * *}$ \\
\hline
\end{tabular}

${ }^{* * *} p<0.001{ }^{* *} p<0.01{ }^{*} p<0.05$

Tekil ilişkilerde bağımsız değişkenler olan Big Five ölçeği alt boyutlarının medyator değişkene etkilerinde anlamlı etkiler EXT değişkeninin $\mathrm{BO}$ değişkenine etkisi $(\beta=-, 885 ; \mathrm{p}<0,05)$, CON değişkeninin BO değişkenine etkisi $(\beta=-, 350 ; \quad p<0,05), \quad$ AGR değişkeninin BO değişkenine olan etkisi $(\beta=, 280 ; p<0,05)$ şeklindedir.

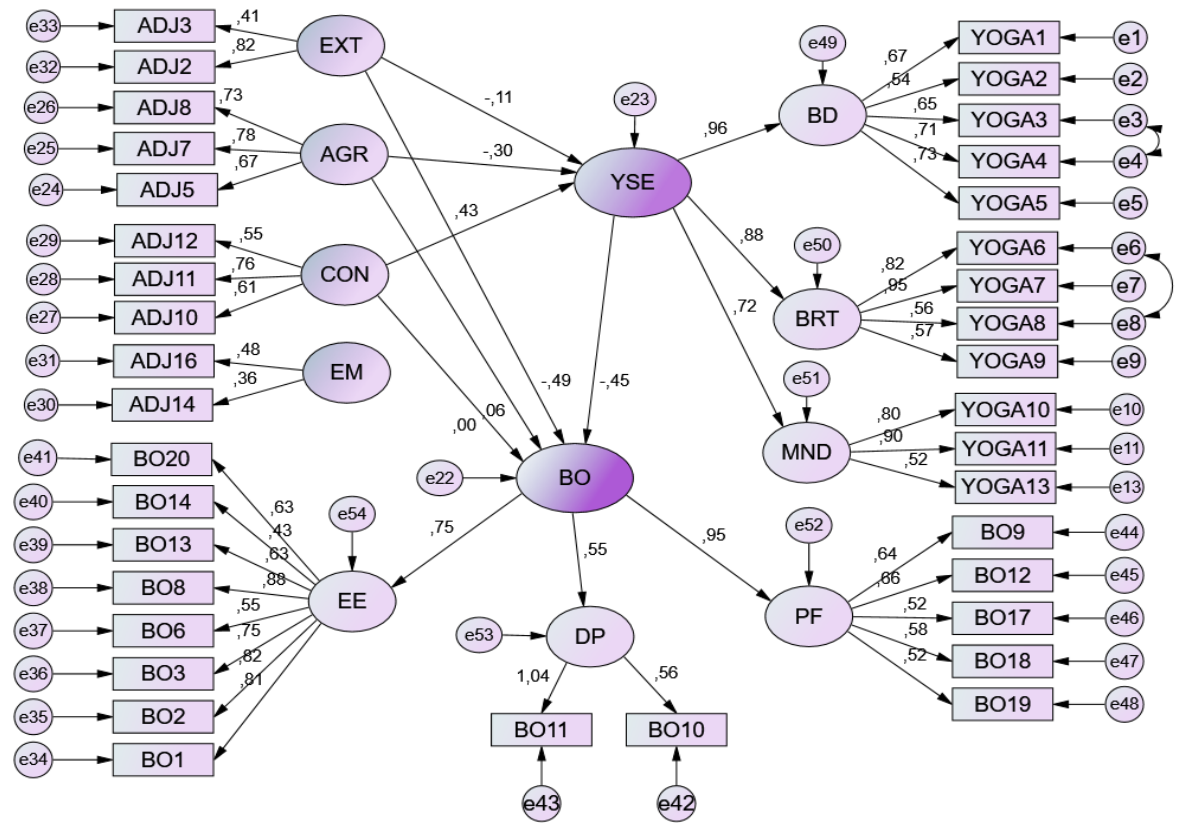

Şekil 5. Araştırmada Test Edilen Çoklu Mediator Model 
Anlamsız olarak bulunmuş olan ilişki ise EM değişkeninin BO değişkenine olan $(\beta=, 056 ; p>0,05)$ etkisidir. Bu durumda YSE değişkeninin $\mathrm{CON}$ değişkeninin $\mathrm{BO}$ değişkenine olan etkisinde aracılık yapma durumu ortadan kalkmaktadır. Aracılık için BO değişkenine anlamlı etkiler olan EXT, CON ve AGR değişkenlerinin alınması yeterli olacaktır.

Mediator model analizinde, model test değerleri $x^{2}$ (1307.841), $x^{2} / d f$ (2.180) olarak hesaplandığından dolayı modelin anlamlı olduğu sonucu çıkmaktadır. Ayrıca hesaplanan uyum indeks kriterleri GFI $(0,824)$, CFI $(0,811)$, SRMR $(0,0864)$, RMSEA $(0,0810)$ kabul edilebilir sınırlara çok yakın olduğu anlaşılmaktadır. Tam mediatörün bulunabildiği modellerin kabul sınırları dahilinde olmaması beklenen bir durumdur. Modelde yer alan etki değerlerinin ayrıntıları aşağıdaki tabloda yer almaktadır.

Tablo 6. Bağımsız, Bağımlı Ve Mediator Değişken Arasındaki Tekil Etki Değerleri

\begin{tabular}{llllllll}
\hline & Eksojen & Etki & Endojen & $\beta$ & Std. $\beta$ & CR & p \\
\hline \multirow{3}{*}{ Bağımsız $\rightarrow$ Mediator } & EXT & $\rightarrow$ & YSE &,- 119 &,- 110 &,- 779 &, 436 \\
& AGR & $\rightarrow$ & YSE &,- 207 &,- 305 & $-2,952$ &, $003^{* *}$ \\
& CON & $\rightarrow$ & YSE &, 283 &, 428 & 2,838 &, $005^{* *}$ \\
Mediator $\rightarrow$ Bağımlı & YSE & $\rightarrow$ & BO &,- 762 &,- 449 & $-3,814$ &, $000^{* * *}$ \\
& AGR & $\rightarrow$ & BO &, 070 &, 061 &, $\mathbf{6 1 8}$ &, $\mathbf{5 3 6}$ \\
Bağımsız $\rightarrow$ Bağımlı & EXT & $\rightarrow$ & BO &,- 890 &,- 487 & $-2,640$ &, $008^{* *}$ \\
& CON & $\rightarrow$ & BO &, 006 &, 005 &, 030 &, 976 \\
\hline
\end{tabular}

${ }^{* * *} p<0.001{ }^{* *} p<0.01{ }^{*} p<0.05$

Modelde EXT değişkeninin YSE değişkenine etki değeri anlamsız ( $\beta=-$ ,110; p>0,05) olduğundan EXT değişkeninin BO değişkenine etkisinde YSE değişkeninin aracılık etkisine bakmanın anlamsız olduğu anlaşılmıştır.

Modelde AGR değişkeninin YSE değişkenine etki değeri anlamlı $(\beta=-$ ,305; $\mathrm{p}<0,05)$ ve YSE değişkeninin BO değişkenine etkisi $(\beta=-, 449 ; \mathrm{p}<0,05)$ anlamlı iken, AGR değişkeninin BO değişkenine olan etki değeri anlamsız $(\beta=, 061 ; p>0,05)$ bulunduğundan AGR'nin BO değişkenine etkisinde YSE değişkeninin tam aracılık etkisi olduğu anlaşılmaktadır. $\mathrm{Bu}$ model ayrica Sobel testi ile de teyit edilecektir. 
CON değişkeninin YSE değişkenine etki değeri anlamlı $(\beta=-, 428$; $p<0,05)$ ve YSE değişkeninin $\mathrm{BO}$ değişkenine etkisi $(\beta=-, 449 ; \mathrm{p}<0,05)$ anlamlı iken, $\mathrm{CON}$ değişkeninin $\mathrm{BO}$ değişkenine olan etki değeri anlamsız $(\beta=, 05 ; \quad p>0,05)$ bulunduğundan $\mathrm{CON}$ değişkeninin BO değişkenine etkisinde YSE değişkeninin tam aracılık etkisi olduğu anlaşılmaktadır. Bu model ayrıca Sobel testi ile de teyit edilecektir.

Analize yönelik akademik makalelerde, Baron ve Kenny'in üç aşamalı şeması kullanılmaktadır ve elde edilen analiz verilerine göre kısmi ya da tam aracılık yönünde karar verilmektedir. Bununla birlikte, aracı etkinin varlığının söz konusu olabilmesi için sağlanması beklenen koşullarla birlikte, eksojen (mediator değişken vasıtasıyla) endojen değişken üzerinde olan dolaylı etkisinin anlamlı olup olmadığını ortaya koymak gerekir. Söz konusu koşulları sağlayabilmek için birçok test kullanılmaktadır. Bu konuda en çok tercih edilen test ise Sobel Test'tir (Sobel, 1982). Sobel Test, $\beta$ olarak adlandırılan, kullanılan değişkenlerin düzeltilmemiş regresyon katsayıları ile bunlara ait standart hata değerlerinin kullanılması ile hesaplanmaktadır.

Tablo 7. Modelde Bulunan Mediator İlişkilerin Sobel Test İle Anlamlılk İncelemesi

\begin{tabular}{lllllll}
\hline Model No & Endogen & Etki & Egsogen & $\boldsymbol{\beta}$ & SD & $\mathbf{p}$ \\
\hline \multirow{4}{*}{1} & AGR & $\rightarrow$ & YSE &,- 207 & .070 & \\
& YSE & $\rightarrow$ & BO & -.762 &, 200 & $\mathbf{0 . 0 1 9 4 8 7 8 3 ^ { * }}$ \\
2 & CON & $\rightarrow$ & YSE &, 283 & .100 & \\
\hline
\end{tabular}

1: Sobel Test: ${ }^{*} p<0,05^{* *} p<0,01$

Tekil ilişlilerde CON değişkeninin $\mathrm{BO}$ değişkenine etkisi $(\beta=-, 350$; $\mathrm{p}<0,05)$ anlamlı iken CON ile BO arasına giren YSE değişkeni ile birlikte CON değişkeninin $\mathrm{BO}$ değişkenine olan etki değeri $(\beta=, 05 ; p>0,05)$ olması durumunun tam aracılık olduğu sobel testinde bulunan $(p<0.05)$ değeri ile teyit edilmiştir.

Tekil ilişlilerde AGR değişkeninin BO değişkenine etkisi $(\beta=, 280$; $\mathrm{p}<0,05)$ anlamlı iken CON ile BO arasına giren YSE değişkeni ile birlikte AGR değişkeninin $\mathrm{BO}$ değişkenine olan etki değeri $(\beta=, 061 ; p>0,05)$ olması durumunun tam aracılık olduğu sobel testinde bulunan $(p<0.05)$ değeri ile teyit edilmiştir. 


\section{Sonuç ve Tartışma}

$\mathrm{Bu}$ çalışmanın amacl, kişilik tiplerine göre bireylerin tükenmişlik durumlarında yoganın aracılık etkisinin sonuçlarını ortaya koymaktır. Bunun için araştırmada kişilik tipleri için Big Five Ölçeği; tükenmişlik düzeyleri için Burnout Ölçeği; yoganın etkisi için de Yoga self efficacy ölçekleri kullanılmıştır. Big five ölçeği literatürden farklı olarak Ext(dışadönüklük), Agr(uyumluluk), Con(özdisiplinli), Em(duygusal istikrar) şeklinde 4 faktör altında toplanmış ve boyutlar bazında da ölçek güvenilir olarak değerlendirilmiştir. Tükenmişlik (Burnout)ölçeği; duygusal tükenme (EE), duyarsızlaşma (DP) ve kişisel başarı (PA) şeklinde 3 faktörde toplanmıştır ve literatür ile uyumludur. Ayrıca tükenmişlik ölçeği, her boyut bazında ölçek güvenilir olarak değerlendirilmiştir. Yoga self efficacy ölçeği ise literatürle uyumlu olarak üç faktör altında toplanmıştır. Beden(BD), nefes(BRT) ve zihin(MND) alt boyutlarından oluşan yoga ölçeği de her boyut bazında güvenilir düzeyde yer almıştır.

Araştırma kapsamında toplanan anket cevapları SPSS ve AMOS programları ile analiz edilmiştir. Ölçeklerin güvenilirliği araştırmasında Cronbahc's Alpha katsayıları kullanılmıştır. Buna göre; araştırma ölçekleri Kişilik tipleri(Big Five), Tükenmişlik(Burnout) ve Yoga self efficacy ölçeklerinin güvenilirlik değerleri sırasıyla (.786), (.809) ve (.875) olarak hesaplanmış ve değerler yüksek güvenilirlik düzeyinde yer almıştır. Ölçeklerin yapı geçerliliğinin incelenmesi için her bir ölçeğe doğrulayıcı faktör analizi uygulanmıştır. Buna göre Kişilik Tipleri ölçeğinin model test değerleri; $x^{2}(45.51), x^{2} / d f(1,625)$ bulunduğundan dolayı doğrulayıc1 faktör analizinin anlamlı olduğu sonucuna varılmaktadır. Modelin uyum indeks olarak adlandırılan kriterleri olan GFI (,949), CFI (,950), SRMR (,075) , RMSEA (,062) ise kabul edilebilir değerler içerisinde bulunduğundan dolayı big five ölçeğinin doğrulayıcı faktör analizinin geçerli olduğu sonucuna ulaşılmaktadır.

Burnout ölçeğinin doğrulayıc faktör analizinde bulunan model test değerleri; kikare (208.21), kikare/df (2.393) olarak hesaplandığından DFA nın anlamlı olduğu sonucuna ulaşılmaktadır. Modelin uyum indeks kriterleri GFI (,911), CFI (,954), SRMR (,069), RMSEA (,072) kabul 
edilebilir aralıklar içinde yer aldığından big five ölçeğinin Doğrulayıcı Faktör analizinin geçerliliğinden söz edilebilir.

Yoga Self-Efficacy ölçeğinin doğrulayıcı faktör analizinde hesaplanan model test değerleri kikare (87.70), kikare/df (1.993) elde edildiğinden dolayı DFA' nın geçerli olduğu söylenebilir. Modelin uyum indeks sonuçları GFI $(0,923)$, SRMR $(0,069)$, CFI $(0,954)$, RMSEA $(0,078)$ kabul edilebilir aralıklar içerisinde bulunduğundan Yoga Self-Efficacy ölçeğinin Doğrulayıcı Faktör analizi geçerlidir denebilir.

Yoganın aracılık etkisinin incelenmesi için Amos programı kullanılarak mediatör araştırması yapılmış ve modellerin anlamlı olduklarının tespiti için $x^{2}, x^{2} / d f$, GFI, CFI, SRMR ve RMSEA değerleri değerlendirilmiştir. Ayrıca, aracı etkinin varlığının kabul edilebilmesi çin sağlanması gereken koşulların yanı sıra, eksojen (mediator değişken vasıtasıyla) endojen değişken üzerindeki dolaylı yoldan olan etkisinin de anlamlı olup olamayacağını ortaya koymak gerekmektedir. Bunun için bu çalışmada Sobel Testi kullanılmıştır.

Kişilerin tükenmişlik düzeylerinin düşürülmesinde veya kişilik tiplerinde olumsuz eğilimin azaltılmasında yoga uygulamalarının etkili olduğu sonucu elde edilmiştir. Düzenli yoga uygulamak, kişilerin bedensel, nefessel ve zihinsel kendilerine vakit ayırmaları olumlu sonuçları beraberinde getirmektedir.

$\mathrm{Bu}$ anlamda yoga uygulamalarının ayrıntılı anlatılmasının, yaygınlaştırılmasının önemli olduğu görülmektedir. 


\title{
EXTENDED ABSTRACT
}

\section{Yoga's Mediation Role in Relation between Personality Types and Burnout Scale}

\author{
Didem Tetik Küçükelçi \\ Gelişim University
}

The aim of this work is to prove the results of yoga's mediatin effects according to personel types of people on burnout situation.

Burnout concept has become surface first by Freudenberger at 1974 . Freudenberger noticed the effects of busy work life on people and the changes cause by this effect and started to research the negative reftections to productivity. And defined burnout "failure, attrition, power and strength reduction or as a result of unsatisfied results, burnout situation at individual's internal sources" (Freudenberger, 1974). Maslach and Jackson (1981) took burnout as a syndrom and developed Maslach Burnout scale as used often in literature. According to Maslach burnout "physical exhaustion seem on people is a syndrom accours, as a job requirement exposed to intensive emotional demands and have to work face to face, long term tiredness, desperate and hopeless feelings reflect to work, life and the other people with a negative behaviour" (Maslach\&Jackson, 1981: 99).

At burnout syndrome primarly individual starts to feels itself insufficient and ends consuming emotional. And then the person, isolate itself from others, staying away and being far from social envirenments and comes to desensitization level. The person at desensitization level feels to start his/herself insufficient at social and work life. However this individual let her/himself to expose of negative assessments like failed, limited and excluded, by the time start to live the fallness of personal success (Cordes \& Dougherty, 1993: 624; Maslach, Schaufeli \& Leiter, 2001: 403 ; Maslach \& Zimbardo, 1982).

Yoga is a word, means to be one, reunite and to be whole in Sanskrit and derived from "yuj" (Patanjali, 2011). Yoga is a way that individual can use to reach his/her pureself, to define themself, to reach the high consciousness and to live with awareness. Yoga is a shape of thought 
philosophy, is a discipline (Rathfisch, 2015). At yoga the principle is the harmony of body, mind and breathe. That is why the yoga applications bases are, ancient breathing technics (pranayama) mind studies and body postures call asana.

Yoga is a system with eight level blended by physical, spiritual, mental and ethical doctrins. Those eight levels are necessary to a journey for return an essence and think about it, understand and apply it. These are; yama, niyama, asana, pranayama, prathayara, dhrana, dhyana, samadhi (Patanjali, 2011). Yama; are the negative behaviours have to stay away like lie, robbery, violence, greedy, desire, obsession and consists the rules like stick to moral rules, not to hurt others. Niyama becomes from the rules of self discipline. Includes the rules of pureness, simplicity, cleanless, to manage desires, satisfaction, education (Patanjali, 2011). To train to get physical, energetic and mental benefits, to keeping the body in spesific postures (Patanjali, 2011).

Pranayama consist the breathing trainings named ancient breathing technics, to heal the mind, to be healthy. Pranayama comes from pranameans life energy; yama-means to be master and pranayama means to be master at energy of life (Şinik E.,2016). For life energy, taking and giving breath correct and conscious is very important. In recent years researches shows; regular breathing exercises help to many physical, spiritual and mental deseases like restlessness, stress, lack of attention, depression, anxiety, unhappiness(sadness), insomnia, cough, asthma, constipation, neck and back pain, respiratory deseases (Joshi, 1983). Pratyahara is to focused to internal world by controlling sense organs. Mind, purifying from external factor and being calm. Dharana is keeping the mind in a center of consciousness in body and stabilize the attention at one point.

When concentrate to a one point, you pass to dhyana. During the concentration mind been forwarding to only one point. Dhyana mean meditation. At people who meditate regularly, seen that their pressure and tension decreased, awarenesses, love and kindness feelings increased. Besides, this people are more happy and peacefull (Hewitt, 1994). At last step is mentioned from Samadhi. It can name by deep diving. While body and senses observing, mind and spirit stays awake (Isherwood, 2006; Nagendra, Nagarathna, Gürelman, 2014; Atılgan, Tarakci, Polat, Algun, 2015). 
According to Krishnamacharya who considered as a father of yoga, this 3 tool basicly explained like below:

1- Body: At yoga, physical postures name by Asana who practice physical regular, harmonize sanas with breath to raise their mental attention.

2- Breath: The studies about breath. It calls pranayama.

3- Mind: It is meditation situation. Meditation is mental silence situation (Desikachar, 1999).

This yoga self-efficacy scale used at this work, has been developed by Gurjeet S. Birdee, Stephanie J. Sohl and Ken Wallston in 2016. This scale consists features of three base tool which are; body, breath and mind.

Personality; It is a life time process consists many factors like genetical factors ,family, social environment and changing living terms at the same time. Because of this wide definition there are a lot of approach to define and explain personality.

Personality is an evolutionary process includes many factors at the same time. It includes many concepts like genetical, byological, enviromental conditions, social environment, variable life conditions. That is why there are a lot of approches trying to explain personality and researches are still continue. According to Burger, personality is a whole of process in personality and consistent distinctive personality behaviours (2006). With this definition Burger emphazises to our specific specialities separate us from the others, not with our common ways. According this thought system, to define personality under spesific headlines, variable theories have been created. In this approaches frame, factor theory is more accepted (Goldberg ,1990; McCrae, Costa, 2003). This theorists show different characteristics than the other personality theorists. This theorist's purpose is as define distinctive characteristic theorists, not to cut the changes or developments forward to behaviours but trying to define. They work as academic researchers rather than therapist. Distinctive characteristic theory is well using approach in present researches (Funder, 2001). Distinctive characteristic theorists gathered under five formats the results of factor analyses and various personality datas (Costa and McCrea, 1988; Goldberg, 1990; Noller, Law and Comrey,1987; Peabody and Goldberg, 1989). For this format even there are different opinions McCrea and Costa at 2003 found five basic 
personality characteristics: harmony, extrovert, self-discipline, open minded to experience and nevrotic.

\section{Method}

165 survey data analyses executed result of survey work applied August 2019-September 2019. 142 of the participants were female and 23 were male. 107-person age 35 and older, 45 attenders age between 30 and 34 . There are 109 people bachelor degree, 71 attenders work experience 16 years and more.

Survey answers analysed SPSS and Amos programmes. Cronbach's Alpha coefficients used to research of scale's reliability. According this; research scales personality types (Big Five), Burnout and Yoga self efficiency scales reliability values calculated $(0,786),(0,809)$ and $(0,875)$ and this values took a place as high reliable level.

To investigate structure validity of scales, correcting factor analyse has been applied to each scale. As a result, Personality Types Scale's model values found; $\chi^{2}(45,51), \chi^{2} / \mathrm{df}(1,625)$ shows DFA is more significant. Model's accordance index values GFI $(0,949)$,CFI $(0,950)$, SRMR $(0,075)$, RMSEA $(0,062)$ are in acceptable limits so Personality Types (Big Five) Scale's correcting factor analyse is valid.

Burnout Scale's correcting factor analyse model test values $\chi^{2}(208,21)$, $\chi^{2} / \mathrm{df}(2,393)$ shows that DFA is significant. Model's accordance index values GFI $(0,911)$, CFI $(0,954)$, SRMR $(0,069)$, RMSEA $(0,072)$ are in acceptable limits so it can be called as Burnout Scale's correcting analyse is valid.

Yoga Self-Efficacy Scale's correcting factor analyses model test values are $\chi^{2}(87,70), \chi^{2} / \mathrm{df}(1,993)$ so can be mentioned that DFA is significant. Model's accordance index values are GFI $(0,923)$, CFI $(0,954)$, SRMR $(0,069)$, RMSEA $(0,078)$ in acceptable limits so can be mention that Yoga Self Efficacy Scale's correcting factor analyse is valid.

To examine yoga mediation effect, mediator research made with Amos and to determinate models signifancies $\chi^{2}, \chi^{2} / \mathrm{df}$, GFI, CFI, SRMR and RMSEA values evaluated. Furthermore, to mention mediation effect besides to provide the neccessary conditions, to prove if indirect effect is 
significant of exogenous (by mediator variable), on endogenous variable. On this work Sobel test used.

\section{Result}

As a results of mediation research, At personality types scale lawer formats the effect value of AGR variable to Yoga YSE variable is significant $(\beta=-0,305 ; p<0,05)$ and while YSE variable effect to Burnout (BO) variable $(\beta=-0,449 ; p<0,05)$ is significant. AGR variable effect to Burnout $B O$ variable value is insignificant $(\beta=0,061 ; p>0,05)$. So it is understood that AGR effect to BO, YSE has full mediation effect.

The individuals in coherent category are in tend to Burnout, yoga effects in a positive way.

Further, as a personality types scales law formats Self-disciplined $(\mathrm{CON})$ variable's effect to YSE variable value is significant $(\beta=-0,428$; $\mathrm{p}<0,05)$ and while YSE variable effect to $\mathrm{BO}$ variable $(\beta=-0,449 ; \mathrm{p}<0,05)$ is significant $C O N$ variable effect to $B O$ variable value is insignificant $(\beta=, 05 ; p>0,05)$ so it is understood that $C O N$ variable effect to $\mathrm{BO}$ variable, YSE has full mediation effect.

As a result, at individuals, to decrease burnout level and to reduce negative tend at personality types yoga applications are effective. At the same time, to apply yoga regularly, as breath and mental to save time to theirself, bring positive results to people. In this meaning, to tell yoga applications detailed and spreading it is very important.

\section{Kaynakça / References}

Algül, R. (2014). Bugün işe gitmesem iş yaşamında tükenmişlik sendromu. (Birinci Baskı). İstanbul: Mitra Yayınları.

Alkan, E. ve ÖzÇoban, F.A. (2017). Yoganın gebelik, doğum ve doğum sonuçları üzerine etkisi. Smyrna Tip Dergisi, 64,71.

Aslan, H., Aslan, R., Kesepara, C., Alparslan, N. ve Ünal, M. (1997). Kocaeli'nde bir grup sağlık çalışanında işe bağlı gerginlik, tükenme ve iş doyumu. Toplum ve Hekim, 12(82), 24-29. 
Atılgan E., Tarakci D., Polat B. ve Algun C. (2015). Sağlıklı kadınlarda Yoga temelli egzersizlerin esneklik, yaşam kalitesi, fiziksel aktivite ve depresyon üzerine etkilerinin araştırılması. Journal of Exercise Therapy and Rehabilitation, 2(2), 41-46.

Bandura, A. (1997). Self-efficacy: The exercise of control. New York, NY, US: W H Freeman/Times Books.

Baş, Ü. (1998). Hatha yoga ve klasik egzersiz yaklaşımının sağlıkl gençlerde postür ve fiziksel uygunluk üzerine etkileri. Bilim Uzmanlığı Tezi. Hacettepe Üniversitesi Sağllk Bilimleri Enstitüsü, Ankara.

Bayram, N. (2013). Yapısal eşitlik modellemesine giriş Amos uygulamaları(Birinci Bask1). Bursa: Ezgi yayınevi.

Bollen, K.A. (1989). Structural Equations with Latent Variables(First ed). New York.

Burger, J. M. (2006). Kişilik. İstanbul: Kaknüs Yayınları.

Broad W.J. (2012). The Science of Yoga (1st ed). New York: Simon \& Schuster.

Büyüköztürk, Ş. (2015). Veri analizi el kitabı istatistik, araştırma deseni SPSS uygulamaları ve yorum (21. Baskı). Ankara: Pegam Yayınevi.

Carrola, P. A., Yu, K., Sass, D. A. and Lee, S. M. (2012). Measurement invariance of the counselor burnout inventory across cultures: $A$ comparison of U.S. and Korean counselors. Measurement and Evaluation in Counseling and Development, 45(4), 227-244.

Meydan, C. H. (2011). Yapısal eşitlik modellenmesi Amos uygulamaları (Birinci Baskı). Ankara: Detay Yayıncilık.

Coote, S., Garrett, M., Hogan, N., Larkin, A. and Saunders J. (2009). Getting the balance right: A randomised controlled trial of physiotherapy and Exercise Interventions for ambulatory people with multiple sclerosis. BMC Neurol, 9, 34.

Cordes, C. L. and Dougherty, T. W. (1993), A review and an integration of research on job burnout. The academy of management review, 18(4), 621 $-656$.

Costa, P. T. and McCrae, R. R. (1988). Personality in adulthood: A six-year longitudinal study of self-reports and spouse ratings on the NEO Personality Inventory. Journal of Personality and Social Psychology, 54(5), 853-863.

Desikachar, T. (1999). The heart of yoga: Developing a personal practice (1 ${ }^{\text {st }}$ ed). Inner Traditions International: Rochester, Vermont. 
Evans, D. D., Carter, M., Panico, R., Kimble, L., Morlock, J.T. and Spears, M. J. (2011). Characteristics and predictors of short-term outcomes in individuals self-selecting yoga or physical therapy for treatment of chronic low back pain. PMR, 2(11), 1006-15.

Field, T. (2011). Yoga clinical research review. Complement Ther Clin Pract, $17(1), 1-8$.

Freudenberger, H. J. (1974). Staff burnout. Journal of Social Issues, 30(1), 159165.

Funder, D. C. (2001). Personality. Annual Review of Psychology, 52(1), 197-221. doi10.1146/annurev.psych.52.1.197.

Goldberg, L. R. (1990). An alternative "description of personality": The Big-Five factor structure. Journal of Personality and Social Psychology, 59(6), 1216-1229.

Gurjeet, S. B., Stephanie J. S. and Ken W. (2016). Development and Psychometric Properties of the Yoga Self-Efficacy Scale (YSES). The official journal of the International Society for Complementary Medicine Research,16,3.

Hall, E., Verheyden, G. and Ashburn A. (2011). Effect of a yoga programme on an individual with Parkinson's disease: A single-subject design. Disabil Rehabil, 33(15-16),1483-9.

Hewitt, J. (1994). Meditation (Teach Yourself). US: McGraw-Hill Inc.

Isherwood, C. (2006). Konsantrasyonun gücü- patanjalinin yoga sutraları. İstanbul: Okyanus Yayınları.

Joshi, K. S. (1983). Yogic pranayama: Breathing for long life and good health(2nd ed). Ind-US.

Kaçmaz, N. (2005). Tükenmişlik (Burnout) sendromu. İstanbul Tıp Fakültesi Dergisi, 68(1), 29-32.

Kahill, S. (1988). Symptoms of professional burnout: A review of the empirical evidence. Canadian Psycholoy, 29(3), 284-297.

Kalaycı, Ş. (2006). SPSS Uygulamalı Çok Değişkenli İstatistik Teknikleri. Ankara: Asil Yayın Dağıtım.

Kline, R. B. (2005). Principles and practice of structural equation modeling (2. ed.). NY: The Guillford Press.

Kocher, H. C. (1971). Construction of a scale for measurement of attitude towards yoga. Yoga Mimamsa, 14, 39-42.

Lee, J., Lim, N., Yang, E. and Lee, S. M. (2011). Antecedents and consequences of three dimensions of burnout in psychotherapists: A 
meta-analysis. Professional Psychology: Research and Practice, 42(3), 252-258.

Maslach, C., Schaufeli, W. B. and Leiter, M. P. (2001). Job burnout. Annual Review of Psychology, 52, 397-422. doi:10.1146/annurev.psych.52.1.397.

Maslach, C. and Jackson S. E. (1981). The measurement of experienced burnout. Journal of Occupational Behaviour, 2, 99-113.

Maslach, C. and Jackson, S. E. (1986). Maslach burnout inventory (2nd edition). Palo Alto, Consulting Psychologists Press.

McCrae, R. R. and Costa, P. T. (2003). Personality in adulthood: A Five-Factor Theory perspective (2nd ed.). New York: Guilford.

Nagendra, H., Nagarathna, R. and Gürelman, A. (2014). Hamilelik ve Yoga. İstanbul: Purnam Yayınları.

Newham, J. J., Wittkowski, A., Hurley, J., Aplin, J. D. and Westwood M. (2014). Effects of antenatal yoga on maternal anxiety and depression: A randomized controlled trial. Depress Anxiety, 31(8), 631-40.

Noller, P., Comrey, A. L. and Law, H. (1987). Cattell, Comrey, and Eysenck personality factors compared: More evidence for the five robust factors? Journal of Personality and Social Psychology, 53(4), 775-782.

Patanjali, (2011). Yoga sutra, içsel özgürlüğün yolu. (M.,A. Işım) İstanbul: Arıtan Yayınevi.

Rathfisch, G. (2015). Gebelikten anneliğe yoga(Birinci Basım). İstanbul: Nobel Tip Kitabevleri.

Salmon, P., Lush, E., Jablonski, M. and Sephton, S. E. (2009). Yoga and mindfulness: Clinical aspects of an ancient mind/body practice. Cognitive and Behavioral Practice, 16(1), 59-72.

Sareen, S., Kumari, V., Gajebasia, K. S. and Gajebasia, N. K. (2007). Yoga: A tool for improving the quality of life in chronic pancreatitis. World Journal of Gastroenterology, 13(391), 7.

Sorosky, S., Stilp, S. and Akuthota, V. (2008). Yoga \& Pilates in the management of low back pain. Curr Rev Musculoskelet Med.,1, 39-47.

Stevens, J. P. (2001). Applied multivariate statistics for the Social Sciences (4th $E d)$. New York:Basic Books.

Sümer, N. (2000). Yapısal eşitlik modelleri: Temel kavramlar ve örnek uygulamalar. Türk Psikoloji Yazıları, 3(6), 49-74.

Şahin, M. (2019a). Korku, kaygı ve anksiyete Bozuklukları. ASEAD,6(10), 117-135.

Şahin, M. (2019b.) İntegratif Psikoterapi Kuramı. ASEAD, 6(8), 147-165. 
Şinik, E. (2016). Nefeste saklı hayat (Birinci Basım). İstanbul: Libros Yayıncllık.

Kaynakça Bilgisi / Citation Information

Tetik Küçükelçi, D. (2021). Kişilerde tükenmişlik ile kişilik özellikleri arasında yoga'nın aracılık etkisi. OPUS-Uluslararası Toplum Araştırmaları Dergisi, 18(40), 2450-2479. DOI: 10.26466/opus. 877462. 